\title{
Tree Pollen Sensitization and Cross-Reaction of Children with Allergic Rhinitis or Asthma
}

\author{
Ye Jin Park, Yoon Ha Hwang \\ Department of Pediatrics, Busan St. Mary's Hospital, Busan, Korea
}

Objectives: Tree pollen causes allergic rhinitis and asthma. We investigated children who diagnosed as rhinitis or asthma, living in Busan, for tree allergen sensitization, component allergen, oral allergy syndrome, and the relationship between pollen counts and allergen sensitization.

Methods: Pollen were collected in Busan, from January 1 to December 31, 2017, using a Rotorod sampler and enumerated using a microscope. We conducted a study of children with rhinitis or asthma at Busan St. Mary's Hospital in 2017, administered an ISAAC questionnaire, and an oral allergy syndrome survey. Serum specific Ig E tests were performed.

Results: Among the 57 patients, the mean age was 9.3 years. The pollen counts in decreasing order were as follows: pine, alder, oak, juniper, beech, ginkgo, and birch. For sensitization, birch and alder 35.1\%, Japanese cedar 19.3\%, juniper $17.5 \%$, pine $10.5 \%$, and Japanese cypress $8.2 \%$. The component Ig E was tested in 27 patients. Bet $\mathrm{v} 1$ had a high correlation with birch, alder, and peach. Bet $\mathrm{v} 2$ showed a statistically significant correlation with all tree pollen except cypress. Bet $\mathrm{v} 4$ did not have any apparent correlation. Bet $\mathrm{v} 6$ had the same pattern as Bet $\mathrm{v} 2$, but correlation coefficient was higher than that of Bet $v 2$. Oral allergy syndrome was noted in 7 patients, including peach, peanut, apple, tomato, kiwi, and sesame.

Conclusions: Alder and juniper are clinically important tree pollens in Busan. These pollens cause sensitization to birch and Japanese cedar by cross-reaction.

Key Words: Allergy, Busan, Pollen

Pollen-related allergic diseases are called pollinosis. The typical diseases include allergic rhinitis, allergic conjunctivitis, and bronchial asthma, while atopic dermatitis and oral allergy syndrome are also thought to be associated according to recent studies. ${ }^{1-4}$ In the US and Europe, studies regarding the distribution of pollen and related diseases have been continuously conducted since 1930's. ${ }^{5-7}$ In South Korea, similar studies regarding the regional distribution of pollen have also been conducted since 1960's. ${ }^{8-10}$ In particular, a nationwide pollen-related study involving children has been conducted by the Korean Academy of Pediatric Allergy and Respiratory Disease since $1997 .^{11}$

Tree pollen is a typical allergen causing pollinosis. In South Korea, there have also been several studies regarding pollen sensitization and

Corresponding Author: Yoon Ha Hwang, Department of Pediatrics, Busan St.Mary's Hospital, 25-14 Yonghoro 232 beon-gil, Nam-gu, Busan 48575, Korea

Tel: +82-51-933-7986 Fax:+82-51-932-8600 E-mail: hyh190@naver.com

Received: Aug. 20, 2019

Revised: Oct. 28, 2019

\section{(6) (1) (2)}

Accepted: Nov. 04, 2019

Articles published in Kosin Medical Journal are open-access, distributed under the terms of the Creative Commons Attribution Non-Commercial License (http://creativecommons.org/licenses/by-nc/4.0/) which permits unrestricted non-commercial use, distribution, and reproduction in any medium, provided the original work is properly cited. 
allergic diseases in children. ${ }^{12-15}$ Sensitization was mostly detected by skin prick tests, ${ }^{12-19}$ while studies regarding sensitization using serum specific immunoglobulin E (serum specific IgE) tests are scarce. In a study by Yang et al., serum specific IgE in children with allergic rhinitis under the age of 18 years was detected by the MAST (multiple allergen simultaneous test), ${ }^{18}$ but not by the ImmunoCap tests. ImmunoCap test has been newly developed, with a quantitative technique, and it can be tested even the patients had medications such as antihistamines. It can be tested even the patients have active skin disease or dermographism.

In the case of allergic sensitization-related studies conducted only in Busan, South Korea, there was a study of allergic sensitization using pollen collection and skin prick tests for 15 years from $1998,{ }^{13}$ but there has been no recent studies conducted in Busan.

This study aimed to investigate the distribution of tree pollen in the Busan area, to examine the status of pollen sensitization in children with allergic rhinitis or bronchial asthma through ImmunoCap tests, and to investigate the recent trend of clinically important tree pollen in children with allergic diseases in the Busan area. This study will be helpful when the physicians in Busan evaluate allergen sensitization.

\section{MATERIALS AND METHODS}

\section{Subjects}

This study was performed after Busan St.
Mary's Hospital Institutional Review Board approval (BSM2016-14). The subjects of this study were children under the age of 18 years who visited the Department of Pediatrics at Busan St. Mary's Hospital in Busan, South Korea, from January 1 to December 31, 2017. The 57 subjects were children who were diagnosed with allergic rhinitis or bronchial asthma by pediatricians and were suspected of having tree pollen allergies with symptoms worsening in the spring.

\section{Methods}

1) History taking and physical examination After obtaining consent from the children and their guardians, data on age, sex, residential area and family history of allergic diseases were acquired. In addition, allergic rhinitis, asthma, and atopic dermatitis were examined, the International Study of Asthma and Allergies in Childhood (ISAAC) written questionnaire and an oral allergy syndrome survey were also conducted.

2) Pollen collection

Pollen was collected from Busan St. Mary's Hospital, located in Yongho-dong, Nam-gu, Busan, South Korea for 1 year from January 1, 2017 to December 31, 2017. A rotorod sampler (Sampler Technologies Inc., Minneapolis, MN, USA) was placed $1.5 \mathrm{~m}$ above the roof of the hospital, and glycerin-applied glass rods for collection were placed in the sampler. Then, pollen was collected daily from 8 am to 8 am the next day (the sampler operates for 144 minutes per day). The collected glass rods were classified by the days of the week (except for Sundays) and 
were collected in collecting boxes.

The glass rods in the sampler were replaced for collection. Each collected glass rod was placed at the grooves of a microscope support, covered with a $22 \mathrm{~mm}$ x $22 \mathrm{~mm}$ cover glass, stained with Calberla's fuchsin staining solution $(10 \mathrm{~mL}$ glycerin, $20 \mathrm{~mL} \mathrm{95 \%} \mathrm{alcohol,} 30 \mathrm{~mL}$ distilled water, $0.2 \mathrm{~mL}$ basic fuchsin), and then identified within 30 minutes. Pollen grains $/ \mathrm{m}^{3}$ was calculated with a 400× optical microscope and recorded.

Pollen was classified according to size, shape, and surface pattern of the grains. Pollen was largely categorized on the basis of their origin, as follows: trees, grasses, and weeds. The tree pollen collected included pine, alder, oak, juniper, beech, ginko and birch.

3) Measurement of serum specific antibody levels using ImmunoCap

Serum specific IgE was measured using the ImmunoCap system (Thermofisher, Uppsala, Sweden), and was investigated for pine (Pinus strobus), alder (Alnus incana), juniper (Juniperus sabinoides), Japanese hop (Humulus scandens), ragweed (Altemisia vulgaris), birch (Betula verrucosa), Japanese cedar (Cryptomenia japonica), cypress (Chamaecyparis obtusa), orchard grass (Dactylis glomerata), house dust mite (Dermatophagoides farina), peach (Prunus persica), and tomato (Lycopersicon lycopersicum). Sensitization was defined as class 1 ( $\geq 0.35 \mathrm{kUA} / \mathrm{L})$. Oak, Beech and Ginko were not investigated.

4) Birch pollen component allergen test

Birch pollen component IgE was tested along with serum specific IgE measurements. Bet v 1 (PR-10), Bet v 2 (Profilin), Bet v 4 (Polcalcin), Bet v 6 (Isoflavonreductase-like and phynylcoumaranbenzylic ether reductase) were tested.

\section{Statistical analysis}

Statistical analysis was performed using the SPSS version 16.0 (SPSS Inc., Chicago, IL, USA). The correlations between pollens were estimated by Pearson correlation. Statistical significance was set at $P<0.05$.

\section{RESULTS}

\section{Characteristics of the subjects}

All the 57 subjects were included in this study. Among them, 26 were male, accounting for $45.6 \%$, and the mean age was 9.3 years. Among allergic diseases (multiple responses possible), allergic rhinitis was the most common ( $\mathrm{n}=56$, $98.2 \%$ ), followed by allergic conjunctivitis $(\mathrm{n}=$ $32,56.1 \%)$, atopic dermatitis $(\mathrm{n}=24,42.1 \%)$, bronchial asthma ( $\mathrm{n}=16,28.1 \%)$, food allergy $(\mathrm{n}=14,24.6 \%)$, and oral allergy syndrome $(\mathrm{n}=$ 7, 12.3\%) (Table 1).

\section{Distribution of pollen collected in 2017}

The most commonly collected pollen during one year from January 1, 2017 to December 31, 2017 was pine $\left(20,858\right.$ grains $\left./ \mathrm{m}^{3}\right)$, followed by alder $\left(4,078\right.$ grains $\left./ \mathrm{m}^{3}\right)$, oak $\left(4,064\right.$ grains $\left./ \mathrm{m}^{3}\right)$, juniper $\left(3,058\right.$ grains $\left./ \mathrm{m}^{3}\right)$, Japanese hop $(1,918$ grains $\left./ \mathrm{m}^{3}\right)$, beech $\left(1,316\right.$ grains $\left./ \mathrm{m}^{3}\right)$, ginkgo (740 grains $/ \mathrm{m}^{3}$ ), orchard grass (222 grains $/ \mathrm{m}^{3}$ ), birch 
(148 grains $\left./ \mathrm{m}^{3}\right)$, and ragweed (100 grains $\left./ \mathrm{m}^{3}\right)$ (Table 2). The monthly distribution of each pollen is shown in Fig. 1. Most of the tree pollen was collected in spring.

\section{Assessment of sensitization using the Im-} munoCap blood testing

The most common allergen found in the test was house dust mite. 47 out of 56 subjects were sensitized to house dust mites, with the highest sensitization rate of $83.9 \%$. The sensitization rates to birch and alder were $35.1 \%$ and $35.1 \%$ (20 out of 57), respectively, that to orchard grass was $21.1 \%$ (12 out of 57 ), that to Japanese cedar was $19.3 \%$ (11 out of 17 ), that to juniper was $17.5 \%$ (10 out of 57 ), that to Japanese hop was $10.9 \%$ (6 out of 55 ), and that to pine and rag- weed was $10.5 \%$ and $10.5 \%$ (6 out of 57 ), respectively. The sensitization to cypress was $8.2 \%$ (4 out of 49), and the sensitization rates to peach and tomato were $21.4 \%$ (6 out of 28 ) and $14.9 \%$ ( 7 out of 47 ), respectively (Table 3 ) (Fig. 2).

\section{Birch pollen component test results}

Birch pollen component testing was performed in 27 out of 57 subjects, of whom, 10 were sensitized to birch, and 11 were sensitized to alder. Bet v 1 (PR-10) showed a high correlation with birch $(r=0.942)$, alder $(r=0.906)$, and peach $(\mathrm{r}=0.857)(P<0.01)$. Bet $\mathrm{v} 2$ (Profilin) showed a statistically significant correlation with all tree pollen except for cypress, orchard grass, and weeds. Bet v 4 (Polcalcin) showed no correlation

Table 1. Demographic data of the patients

\begin{tabular}{lc}
\hline \multicolumn{1}{c}{ Characteristic } & Value \\
\hline Total number & 57 \\
Male:Female & $26: 31$ \\
Age(Mean \pm SD) & $9.3 \pm 2.89$ \\
Agelyr), $\mathrm{n}(\%)$ & \\
$<5$ & $5(8.8)$ \\
$6-10$ & $33(57.9)$ \\
$11-15$ & $17(29.8)$ \\
$>16$ & $2(3.5)$ \\
Disease, n(\%) & $56(98.2)$ \\
Allergic rhinitis & $32(56.1)$ \\
Allergic conjunctivitis & $24(42.1)$ \\
Atopic dermatitis & $16(28.1)$ \\
Bronchial asthma & $14(24.6)$ \\
Food allergy & $7(12.3)$ \\
Oral allergy syndrome &
\end{tabular}


Kosin Medical Journal 2019;34:126-137.

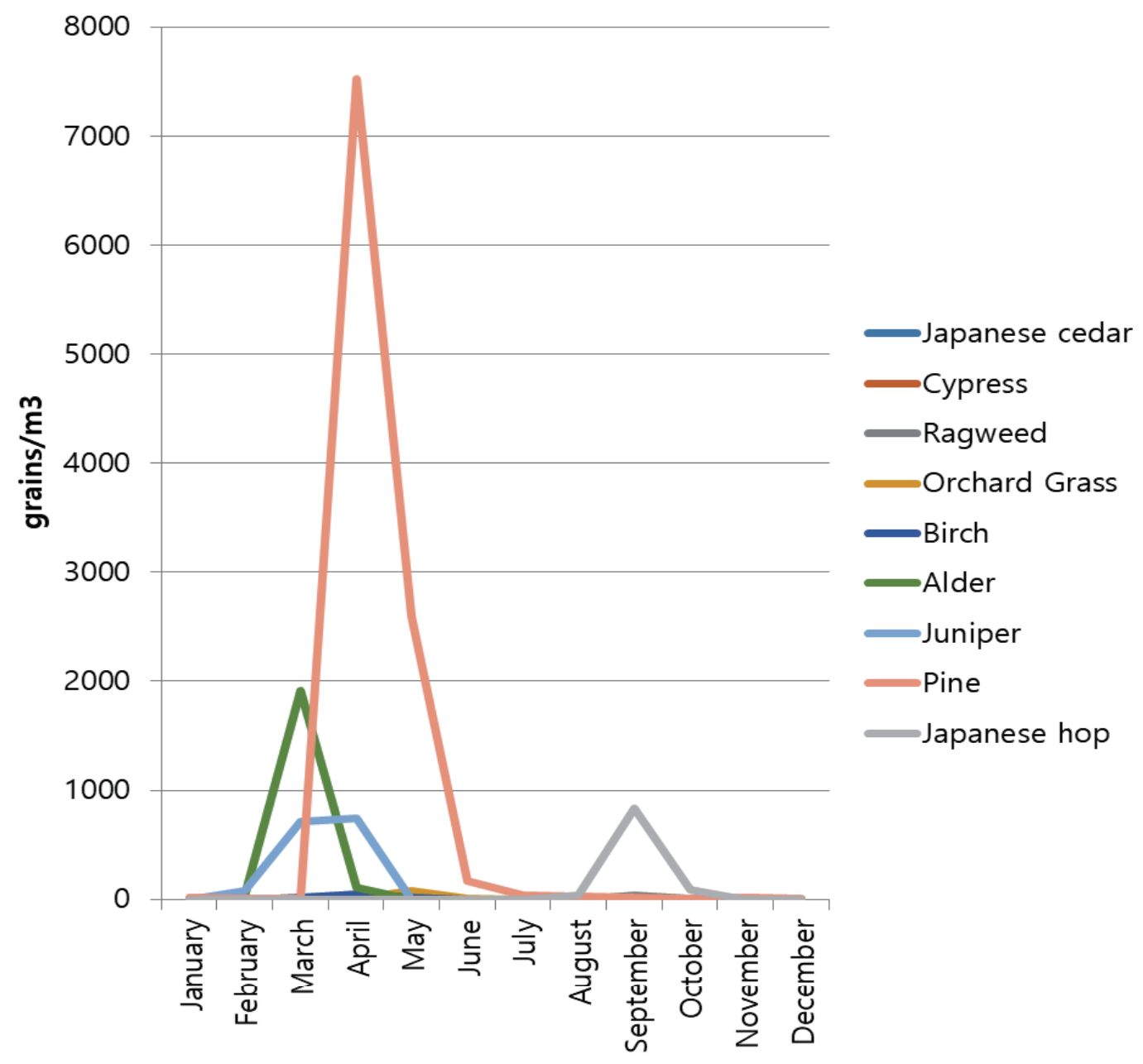

Fig. 1. Monthly pollen in Busan (2017)

Table 2. Total count of tree pollens in Busan, 2017

\begin{tabular}{lc}
\hline \multicolumn{1}{c}{ Pollen } & grain $/ \mathrm{m}^{3}$ \\
\hline Pine & 20,858 \\
Alder & 4,078 \\
Oak & 4,064 \\
Juniper & 3,058 \\
Beech & 1,316 \\
Ginko & 740 \\
Birch & 148 \\
Japanese cedar & 0 \\
\hline
\end{tabular}




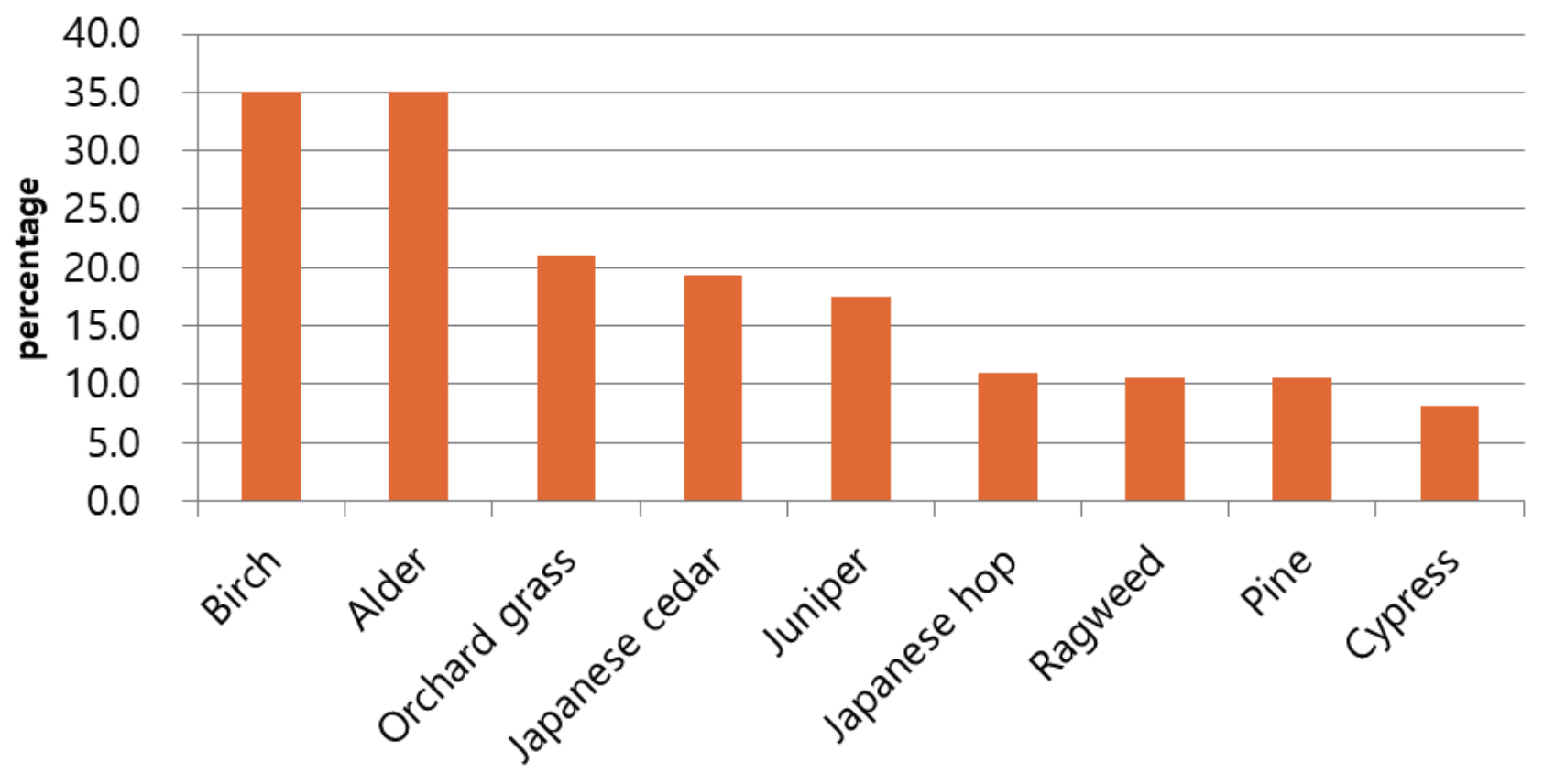

Fig. 2. The sensitization rates of the patients

Table 3. Serum specific Ig E by Immunocap

\begin{tabular}{lcc}
\hline & Sensitized patients/ total patients & Sensitization rate (\%) \\
\hline Pine & $6 / 57$ & 10.5 \\
Alder & $20 / 57$ & 35.1 \\
Juniper & $10 / 57$ & 17.5 \\
Japanese hop & $6 / 55$ & 10.9 \\
Ragweed & $6 / 57$ & 10.5 \\
Birch & $20 / 57$ & 35.1 \\
Japanese cedar & $11 / 57$ & 19.3 \\
Cypress & $4 / 49$ & 8.2 \\
Orchard grass & $12 / 57$ & 21.1 \\
HDM* & $47 / 56$ & 83.9 \\
Peach & $6 / 28$ & 21.4 \\
Tomato & $7 / 47$ & 14.9
\end{tabular}

Oak, Beech and Ginko were not investigated.

*HDM: house dust mite 
because no patient was sensitized. Bet v 6 also showed statistically significant correlation with all pollen except for cypress $(P<0.01)$.

\section{Correlation between pollen}

Considering the tree pollen in Busan in 2017, alder among the Fagales and pine among the Pinales were the most dominant pollen types, followed by juniper pollen. The actual sensitization rates observed through the ImmunoCap testing were high for birch and Japanese cedar, which appears to be due to cross-reactivity between trees belonging to the same order. The correlation coefficient between alder and birch was $r=$ $0.994, P<0.001$, showing a significant correlation. The correlation coefficient between juniper and Japanese cedar was $\mathrm{r}=0.879$ and $P<0.001$, also showing a high correlation (Fig. 3).

\section{Oral allergy syndrome}

Out of the 57 subjects, 7 presented with oral allergy syndrome symptoms. The mean age was $10.6(\mathrm{SD} \pm 3.64)$ years, higher than the mean age

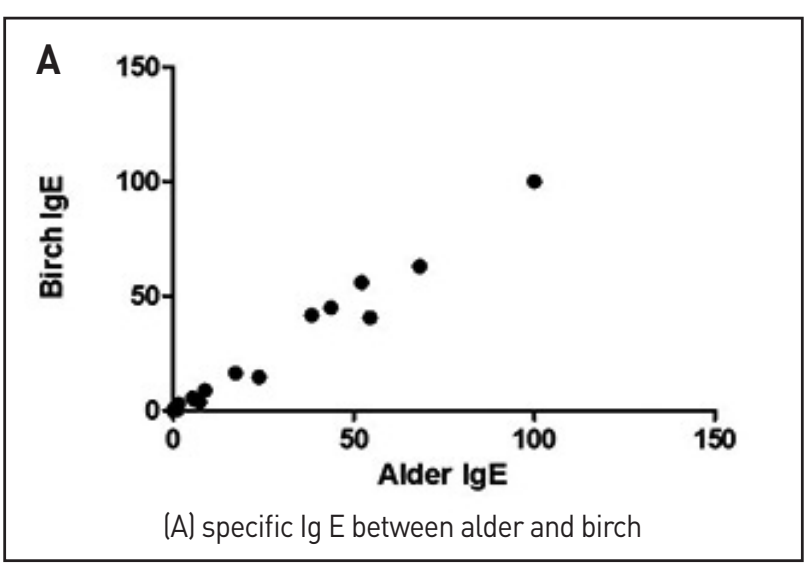

of all subjects. The causative foods included peach $(n=4)$, peanut $(n=3)$, apple $(n=2)$, nuts $(\mathrm{n}=1)$, tomato $(\mathrm{n}=1)$, kiwi $(\mathrm{n}=1)$, and sesame seeds $(n=1)$ (multiple responses possible). Pollen sensitization tests showed that 5 subjects were sensitized to birch and alder, 4 were sensitized to juniper, and 2 were sensitized to pine. Of 7 subjects, 3 underwent allergen component testing simultaneously. The mean value of Bet v 1 was $67.3 \mathrm{kUA} / \mathrm{L}$, the mean value of Bet $\mathrm{v} 2$ was $3.42 \mathrm{kUA} / \mathrm{L}$, the mean value of Bet $\mathrm{v} 4$ was 0 $\mathrm{kUA} / \mathrm{Lm}$, and the mean value of Bet $\mathrm{v} 6$ was 2.29 $\mathrm{kUA} / \mathrm{L}$, indicating that the mean value of Bet $\mathrm{v}$ 1 was significantly higher.

\section{DISCUSSION}

The results of this study showed that in terms of tree pollen in Busan in 2017, pine pollen was the dominant, followed by alder, oak, juniper, beech, ginkgo, and birch. These results are similar to those of a study regarding the nationwide

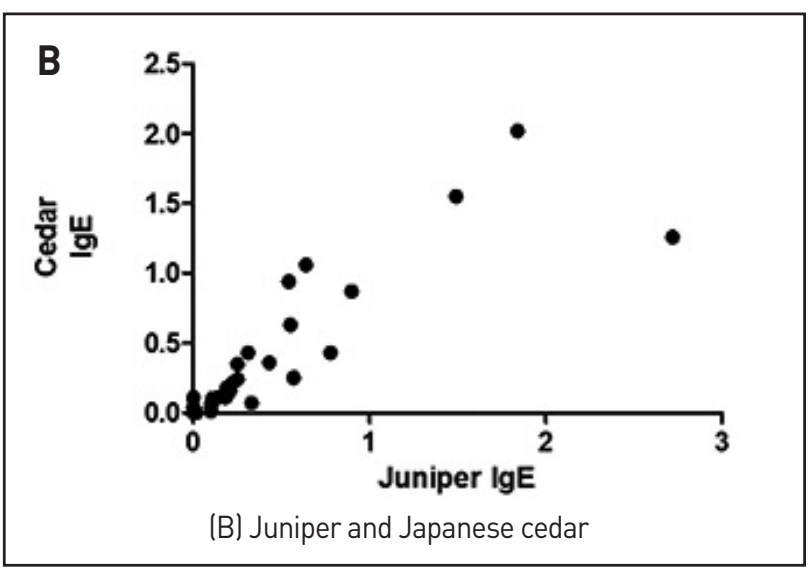

Fig. 3. The correlation of specific $\lg E$ between alder and birch (A), juniper and Japanese cedar (B) 
distribution of pollen for 11 years starting in 1997, reporting that the major tree pollen comprised pine, oak, alder, and birch, but were slightly different from its reporting on birch and juniper. ${ }^{20}$ A study by Sung et al., regarding airborne pollen in Busan in 1998 - 2012 also reported that the major tree pollen in Busan were, in descending order, pine, alder, oak and juniper, and that in skin prick tests in children, the sensitization rates to birch (15.1\%), oak (14.7\%) and juniper (14.1\%) among the Fagales were detected, but the Pinales except for pine were not tested. $^{13}$

In this study, sensitization to pollen was identified with serum specific IgE using ImmunoCap assays. The findings showed that birch and alder had the highest sensitization rate, with $35.1 \%$ for each, while the collected pollen counts were, in descending order, of pine, alder and oak. Although birch pollen was not much collected, the sensitization rate to birch was found to be high. This is thought to be due to the cross-reactivity of the sensitization to alder and oak, as both belong to the same Fagales together with birch. ${ }^{21}$ In addition to the Fagales, Japanese cedar among the Pinales showed the highest sensitization rate, with $19.3 \%$, followed by juniper (17.5\%), pine $(10.5 \%)$ and cypress $(8.2 \%)$. In view of the fact that Japanese cedar pollen was rarely found in the actual pollen collection, it is inferred that a high sensitization rate to Japanese cedar was due to cross-reactivity with juniper. However, the sensitization rate to Japanese cedar was higher than that to juniper; further studies regarding this issue are thus needed. The allergen Jun a 1 from juniper is known to have a high degree of homology with Japanese cedar and cypress, and crossreactivity between juniper, Japanese cedar and cypress has been reported. ${ }^{22,23}$

In this study, the correlation between juniper and Japanese cedar was found to be $\mathrm{r}=0.879(P=$ 0.000 ), and between juniper and cypress was found to be $r=0.120(P=0.412)$. In light of this, allergens from juniper are highly likely to have components that cross-react only with Japanese cedar, and further studies regarding this are needed.

Pine pollen was the most abundant tree pollen, accounting for $60.9 \%$ of the total. However, the actual sensitization rate to pine was only $10.5 \%$ $(n=6)$, which was similar to the results of a previous skin prick testing performed in this hospital. ${ }^{13}$ In general, pine pollen is known not to cause allergic diseases due to its low antigenicity. ${ }^{24}$

Bet v 1 (PR-10) is a major allergen from oak and is homologous to Aln g 1 (alder), Car b 1 (hornbeam), Cas s 1 (chestnut tree), Cor a 1 (hazel), Fag s 1 (European beech), Ost c 1 (hop hornbeam), and Que a 1 (oak). Bet v 1 (PR-10) is known to have high cross-reactivity in oak allergies and is known to be highly associated with oral allergy syndrome..$^{25,26}$ The results of this study also showed that children sensitized to PR10 proteins were more likely to present with oral allergy syndrome.

Bet v 2 (Profilin) is known as a pan-allergen, ${ }^{27,28}$ and it is positive in $10-20 \%$ of patients with pollen allergy. ${ }^{28}$ In this study, Bet v 2 showed a statistically significant correlation with most 
trees, grasses and weeds except for cypress, indicating a pan-allergen pattern. However, it was shown to be less correlated with oral allergy syndrome.

Bet v 4 (Polcalcin) is also a pan-allergen, and the sensitization rate has been reported to be less than $10 \% .{ }^{29}$ In this study, none of the subjects was sensitized to Bet $v 4$, and its clinical significance in South Korea is thought to be small.

Bet $\mathrm{v} 6$ is an isoflavone reductase, a minor allergen formerly called Bet $\mathrm{v} 5$, which is involved in the defense function of plants. It shows crosssensitization in about $32 \%$ of birch allergies, and is known to be clinically significant in oral allergy syndrome. ${ }^{30}$ In this study, Bet v 6 was correlated with most tree pollen except for cypress, but the correlation coefficient was low, and it also had a low correlation with oral allergy syndrome.

Oral allergy syndrome was observed in 7 (12.3\%) out of all 57 children. In serum specific IgE tests, 5 out of 7 children were co-sensitized to birch and alder, and 4 were sensitized to juniper. One child showed no sensitization to any of the allergens in the tests, and it was doubted whether the child had oral allergy syndrome. Of 7 children with oral allergy syndrome, 3 underwent allergen component testing. The mean value of Bet v 1 was significantly high, with 67.3 kUA/L. Similarly, a study by Choi et al. also found that only Bet $\mathrm{v} 1$ tested positive in Korean children with oral allergy syndrome, ${ }^{26}$ which was similar to the results of this study. It is inferred that oral allergy syndrome symptoms in Korean children are highly likely to be associated with
Bet v 1 .

This study has a limitation in that although allergen component testing was performed, the number of subjects undergoing the testing was small. In particular, birch component testing was performed in this study, but only 10 children sensitized to birch underwent the testing. Therefore, the test results were of low statistical significance.

Another limitation is that ImmunoCap testing was not performed in all 57 children and could not be performed for some allergens. In view of the fact that under the current health insurance scheme, ImmunoCap testing can be performed for a maximum of 12 kinds of allergens. When skin prick testing is feasible, For a maximum of 6 kinds of allergens testing is possible. Therefore it could not be performed for more kinds of allergens. In such a situation, extensive allergen testing could not be performed for all collected species. Further studies regarding this are needed in the future.

In conclusion, alder and juniper are the clinically important tree pollen for children with allergic rhinitis and patients with asthmas in Busan. These pollens cause sensitization to birch and Japanese cedar by cross-reaction. Considering these points, it is thought that more appropriate testing items can be selected in allergy testing in Busan.

\section{ACKNOWLEDGEMENT}

We referred to the information on the distribution of pollen provided by Professor Jae-Won Oh 
and Professor Young-Jean Kim, Hanyang University Guri Hospital, South Korea.

\section{REFERENCES}

1. Lewis WH, Vinay P, Zenger VE. Airborne and allergenic pollen of North America. Baltimore: Johns Hopkins University Press; 1983.

2. Nilsson S, Praglowski J, Nilsson L. Atlas of airborne pollen grains and spores in northern Europe. Stockholm: Almquist \& Wiksell International; 1977.

3. Nilsson ST, Spieksma FM. Traveller's allergy service guide. Stockholm: Palynological Laboratory, Swedish Museum of Natural History; 1992.

4. Kim JH, Kim SH, Park HW, Cho SH, Chang YS. Oral allergy syndrome in birch pollensensitized patients from a Korean university hospital. J Korean Med Sci 2018;33:e218.

5. Durham OC. Incidence of ragweed pollen in United States during 1929. JAMA 1930;94:1907-11.

6. Lewis WH, Imber WE. Allergy epidemiology in the St. Louis, Missouri, area. III. Trees. Ann Allergy 1975;35:113-9.

7. Al-Doory Y, Domson JF, Best J. Further studies of the airborne fungi and pollens of the Washington, D.C. metropolitan area. Ann Allergy 1982;49:265-9.

8. Hong CS, Hwang Y, Oh SH, Kim HJ, Huh KB, Lee SY. Survey of the airborne pollens in Seoul, Korea. Yonsei Med J 1986;27:114-20.
9. Kim HS, Lee MK, Park HS, Kim HJ, Hong CS. Pollen counts in the air of Seoul during 88 Seoul Olympics from September 1st to October 10th, 1988. Allergy 1989;9:564-70. 10. Min KU. Aerobiological and allergological study for airborne pollen in Seoul. Allergy 1984;4:1-20.

11. Oh JW, Lee HR, Kim JS, Lee KI, Kang YJ, Kim SW, et al. Aerobiological study of pollen and mold in the 10 states of Korea. Pediatric Allergy Respir Dis 2000;10:22-33. 12. Kim TB, Kim KM, Kim SH, Kang HR, Chang YS, Kim CW, et al. Sensitization rates for inhalant allergens in Korea; a multi-center study. J Asthma Allergy Clin Immunol 2003;23:483-93.

13. Sung MS, Park YJ, Park GH, Oh JW, Kim SW. The correlation between allergy sensitization rate in pediatric and aerobiological study for airborne pollen in Busan for 15 years. Allergy Asthma Respir Dis 2014;2:3847.

14. Choi SW, Lee JH, Kim YH, Oh IB, Choi KR. Association between the sensitization rate for inhalant allergens in patients with respiratory allergies and the pollen concentration in Ulsan, Korea. Korean J Med 2014;86:453-61.

15. Park HJ, Lim HS, Park KH, Lee JH, Park JW, Hong CS. Changes in allergen sensitization over the last 30 years in Korea respiratory allergic patients: a single-center. Allergy Asthma Immunol Res 2014;6:43443.

16. Kim J, Hahm MI, Lee SY, Kim WK, Chae 
Y, Park YM, et al. Sensitization to aeroallergens in Korean children: a population-based study in 2010. J Korean Med Sci 2011;26:11 65-72.

17. Jeon BH, Lee JC, Kim JH, Kim JW, Lee HS, Lee KH. Atopy and sensitization rates to aeroallergens in children and teenagers in Jeju, Korea. J Asthma Allergy Clin Immunol 2010;30:14-20.

18. Yang EA, Park YM, Kim KH, Lee HJ, Kim HS, Chun YH, et al. The association between nasal eosinophilia and aeroallergen sensitization in children and adolescents with rhinitis. Allergy Asthma Respir Dis 2018;6:161-7.

19. So HJ, Moon SJ, Hwang SY, Kim JH, Jang HJ, Jo JH, et al. Characteristics of airborne pollen in Incheon and Seoul (2015-2016). Asia Pac Allergy 2017;7:138-47.

20. Park KJ, Kim HA, Kim KR, Oh JW, Lee SY, Choi YJ. Characteristics of regional distribution of pollen concentration in Korean Peninsula. Korean J Agric Forest Meterol 2008;10:167-76.

21. Valenta R, Breiteneder H, Pettenburger K, Breitenbach M, Rumpold H, Kraft D, et al. Homology of the major birch-pollen allergen, Betv I, with the major pollen allergens of alder, hazel, and hornbeam at the nucleic acid level as determined by cross-hybridization. J Allergy Clin Immunol 1991;87:67782.

22. Midoro-Horiuti T, Goldblum RM, Kurosky A, Goetz DW, Brooks EG. Isolation and characterization of the mountain cedar (Ju- niperus ashei) pollen major allergen, Jun a 1. J Allergy Clin Immunol 1999;104:608-12.

23. Schwietz LA, Goetz DW, Whisman BA, Reid MJ. Cross-reactivity among conifer pollens. Ann Allergy Asthma Immunol 2000;84:87-93.

24. Harris RM, German DF. The incidence of pine pollen reactivity in an allergic atopic population. Ann Allergy 1985;55:678-9.

25. Bufe A, Spangfort MD, Kahlert H, Schlaak M, Becker WM. The major birch pollen allergen, Bet v 1, shows ribonuclease activity. Planta 1996;199:413-5.

26. Choi WB, You JS, Yi YY, Jeong SI, Song JS, Yang S, et al. Component-resolved diagnosis using microarray for diagnosing hypersensitivity to raw fruits in birch pollen sensitized children. Allergy Asthma Respir Dis 2015;3:200-5.

27.Valenta R, Duchêne M, Vrtala S, Valent P, Sillaber C, Ferreira F, et al. Profilin, a novel plant pan-allergen. Int Arch Allergy Immunol 1992;99:271-3.

28.Vieths S, Scheurer S, Ballmer-Weber B. Current understanding of cross-reactivity of food allergens and pollen. Ann NY Acad Sci 2002;964:47-68.

29. Asero R, Jimeno L, Barber D. Preliminary results of a skin prick test-based study of the prevalence and clinical impact of hypersensitivity to pollen panallergens (polcalcin and profilin). J Investig Allergol Clin Immunol 2010;20:35-8.

30. Karamloo F, Schmitz N, Scheurer S, Foetisch K, Hoffmann A, Haustein D, et al. 
Molecular cloning and characterization of a birch pollen minor allergen, Bet v 5 , belonging to a family of isoflavone reductase-related proteins. J Allergy Clin Immunol 1999;104:991-9. 